\title{
High Performance Accelerated Tests to Evaluate Hard Cr Replacements for Hydraulic Cylinders
}

\author{
Emmanuel P. Georgiou 1,*, Dirk Drees ${ }^{1} \oplus$, Greet Timmermans ${ }^{2}$, Alexandros Zoikis-Karathanasis ${ }^{3}$, \\ Marta Pérez-Fernández ${ }^{4}$, Luca Magagnin ${ }^{5}$ (D) and Jean-Pierre Celis ${ }^{6}$ (D) \\ 1 Falex Tribology, Wingepark 23B, B3110 Rotselaar, Belgium; ddrees@falex.eu \\ 2 Tenneco, Poort Sint-Truiden, Sint-Jorisstraat 4520, 3800 Sint-Truiden, Belgium; Greet.Timmermans@driv.com \\ Creative Nano, Leventi 4, 12132 Peristeri, Greece; alexkar1978@hotmail.com \\ 4 AVANZARE Innovacion Tecnologica S.L., 26370 Navarrete, Spain; marta@avanzare.es \\ 5 Dipartimento di Chimica, Materiali e Ingegneria Chimica Giulio Natta, Politecnico di Milano, \\ 20131 Milano, Italy; luca.magagnin@polimi.it \\ 6 Department of Materials Engineering (MTM), K.U. Leuven, Kasteelpark Arenberg 44, 3001 Leuven, Belgium; \\ jean-pierre.celis@kuleuven.be \\ * Correspondence: egeorgiou@falex.eu; Tel.: +32-016-40-79-65
}

\section{check for}

updates

Citation: Georgiou, E.P.; Drees, D.; Timmermans, G.;

Zoikis-Karathanasis, A.;

Pérez-Fernández, M.; Magagnin, L.;

Celis, J.-P. High Performance

Accelerated Tests to Evaluate Hard $\mathrm{Cr}$

Replacements for Hydraulic

Cylinders. Coatings 2021, 11, 1511.

https://doi.org/10.3390/

coatings11121511

Academic Editor: Huirong Le

Received: 25 October 2021

Accepted: 6 December 2021

Published: 8 December 2021

Publisher's Note: MDPI stays neutral with regard to jurisdictional claims in published maps and institutional affiliations.

Copyright: (c) 2021 by the authors. Licensee MDPI, Basel, Switzerland. This article is an open access article distributed under the terms and conditions of the Creative Commons Attribution (CC BY) license (https:// creativecommons.org/licenses/by/ $4.0 /)$.

\begin{abstract}
To prolong the lifetime of hydraulic cylinders, a wear-resistant low-friction surface is required. Until now, hard $\mathrm{Cr}$ coatings were the best materials for this. However, in recent years, there has been an increasing pressure on the manufacturing of hard $\mathrm{Cr}$ plating and plated products, because of environmental and health hazards. The replacement of these coatings by alternatives has not been highly successful yet, because it requires extensive component testing, which is costly and time-consuming and thus not appropriate for material development. For this reason, there is a high need to develop tribological methods that simulate hydraulic cylinders' component-testing closely. In addition, these new methods should also provide additional information (e.g., friction evolution) that can assist in the further development and optimization of alternative coatings. Having the above in mind and building on an existing method from the American Society for Testing and Materials (ASTM G133), a new test method that allows users to test directly on hydraulic cylinders was developed. This method can provide a relative ranking of both the wear resistance and frictional performance of alternative coatings in direct comparison to state-of-the-art hard Cr. Importantly, the method is repeatable and has a much shorter test duration than full-scale component tests, thereby accelerating material development significantly.
\end{abstract}

Keywords: hydraulic cylinders; friction; wear; hard chrome; electrodeposits; tribological method

\section{Introduction}

On a yearly basis, 50 million-100 million hydraulic cylinders, with a retail value of more than one billion dollars, are produced [1]. A typical European country has a demand for over 5 million units per year on new cars and over 1 million replacement units, and the US market is several times larger than that [1]. In China alone, the number of passenger cars has reached above 200 million in 2017, with an estimated annual increase of about $10 \%-12 \%$ [2]. Hydraulic cylinders are key components that determine the functionality of automobiles, as they provide improved grip when the vehicle turns and brakes, and they largely determine onboard comfort. To improve their performance and lifetime, friction and wear should be minimized, and thus a hard chrome coating with a well-controlled surface finish is applied on the rod to improve its tribological performance [1].

The most widely used method to achieve this is by electrodeposition [3,4], from solutions containing chromic acid and catalytic anions. However, the extremely negative environmental impact of hard chromium plating processes by the use of the carcinogenic hexavalent chromium has led to directives and legislation by the European Commission 
that restrict the use of this method [5]. The sunset date for using hexavalent chromium in Europe was set for September 2017, and despite an extension, a new sunset date is approaching. The lack of alternative materials has resulted in the continuation of the production and usage of hard chrome coatings at higher costs. Thus, one of the main goals in surface engineering is still to develop alternative coatings, preferably via electrodeposition, so that the production lines in the industry can adapt as easily as possible to these new coatings.

Up until now, several electrodeposited coatings, such as Ni-P [6], Ni-Co [7], Ni-W [8], Ni-Sn [9], Co-Sn [10], Co-W [11], Co-Ni-P [12], etc., have been considered as candidate replacements for hard $\mathrm{Cr}$. The properties of these coatings can be improved by co-depositing with hard particles [13] and/or by refining their layering [14]. A nice overview on tribological coatings for hard chrome replacement is given in the recently published article by Wang et al. [15]. Despite the wide variety of existing coatings, very few of them have found their way into industrial applications, such as the development of hydraulic cylinders. One of the main reasons for this lack of implementation is the cost and time needed to do component tests. Long tests are not appropriate for material development. Faster (accelerated) tests are being used, but due to their simplified tribological contacts, they do not properly simulate the actual application. For example, pin-on-disk tests under dry conditions are frequently used to provide relative ranking of coatings. However, in hydraulic cylinders, the contact pressures are generally orders of magnitude lower than in a ball-on-flat contact (area contact between the rod guide and rod), and the contact always operates under a thin layer of lubrication. Our review of the literature indicated that there are two main approaches on how to evaluate the tribological behavior of hydraulic cylinders. The first one is by mathematical simulation/modeling [16-20], whereas the second one is by developing new lab-scale test procedures [21-24]. Currently, both approaches have certain limitations. To develop correct simulations/models, the input of "relevant" experimental data is needed, and these data are rarely available. This is especially the case for new materials, where their tribological behavior is yet to be defined. Lab-scale tests are more applicable for material development, as long as they correlate well with the component behavior. Unfortunately, until now lab-scale tribological tests [21-23] focus only on the frictional aspect, which determines the performance of hydraulic cylinders, but not on the wear which dictates the lifetime of this component. Moreover, the lab-scale tests that do measure wear [24] use simplified contacts and different contact geometries that do not closely resemble the actual contact.

Having the above in mind, there is clearly a strong need to develop new or to modify existing tribological methods to simulate closely the actual component. To achieve this, the same wear mechanism should be generated in the tribological method. Furthermore, additional information, such as the friction evolution, should be provided to further assist in the development and optimization of candidate coatings. This work was based on ASTM G133 [25], which covers laboratory procedures for determining the sliding wear of materials by using a linear, reciprocating ball-on-flat plane geometry. This method includes both unlubricated and lubricated conditions. However, the proposed test method was developed to test directly on hydraulic cylinders' components (Figure 1) and not on simplified test coupons. The aim is to be as a close as possible to the end application and to better understand the wear mechanisms that take place. The advantages and research potentials of this method are highlighted.

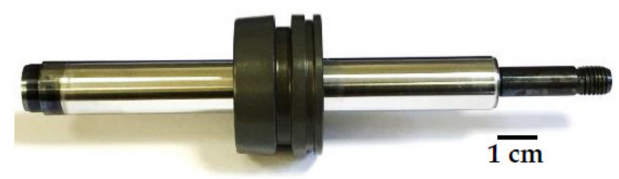

Figure 1. Anodized $\mathrm{Al}$ rod guide and hard $\mathrm{Cr}$ rod. 


\section{Materials and Methods}

In all experiments, anodized $\mathrm{Al}$ rod guides (production parts) were used, and $14 \mathrm{~mm}$ $\varnothing$ hard $\mathrm{Cr}$ reference rods and various $\mathrm{Ni}$ and $\mathrm{Cr}$ based nanostructured electrodeposits were compared with each other. The hard $\mathrm{Cr}$ coated rods serve as the reference material.

To find the most appropriate test method, we applied the Tribological Aspect Number (TAN) approach [26]. This method consists of defining four key criteria, namely type of motion, area of contact, loading type and entry angle of a lubricant (see Figure 2). In this way, complex tribological contacts can be described by a four-digit number that corresponds to one or more possible tribological tests. By analyzing the contact between the rod guide and the coated rod, we determined the following:

1. The motion is reciprocating sliding.

2. The contact geometry is area to area.

3. A unidirectional lateral load is applied.

4. A monolayer of oil is pushed into the tribo-contact.

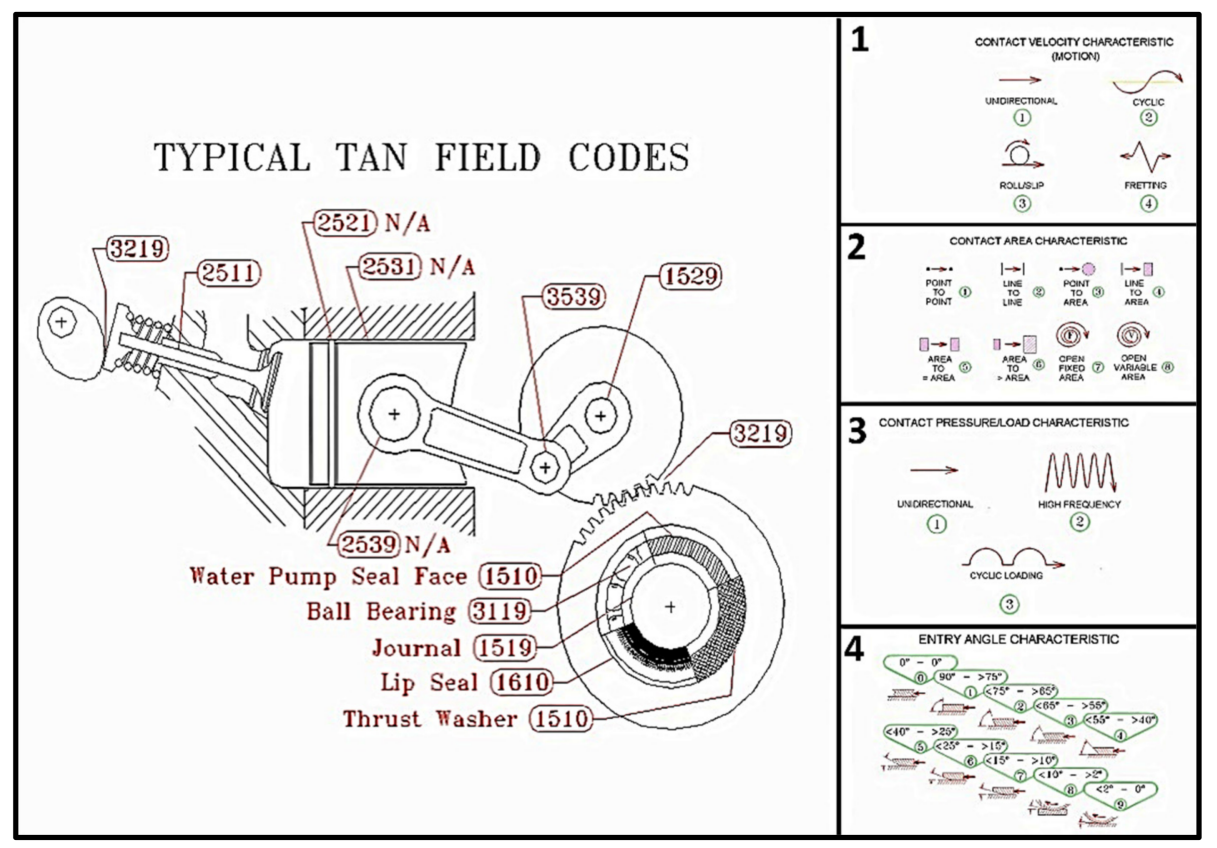

Figure 2. Schematic showing examples of TAN numbers and the four main criteria for number selection [26].

Thus, the TAN number for this tribo-system is 4510. Based on this number and the authors experience, a TE-77 tester (Phoenix Tribology, Kingsclere, UK) was adapted at Falex Tribology NV to mimic the field test behavior of the actual hydraulic cylinders.

To get an even better match between the in-field conditions and the lab-scale testing, a modification on this tester was performed to use the actual components. Because of this, we can test the materials, as well as the surface finish and any production parameters of real components directly in the tribotest. A schematic is given in Figure 3a,b. The idea is to connect the driving arm of the tester to the coated rod to reproduce the reciprocating motion (Figure 3c) and use the tester's loading system to apply a unidirectional lateral loading onto the rod against the rod guide (Figure 3d). In field practice, such lateral forces can be caused by an impact and/or vibrations of the system, which result in a bending of the hydraulic cylinders. Furthermore, the localized contact between the rod guide and the rod initiates additional friction that increases the level of vibration transferred from the road and to localized wear of the rod guide and/or rod that leads to oil leakage. Thus, lateral loading impacts both the performance (smoothness during riding) and lifetime of 
hydraulic cylinders. To mimic the oil film formation in a hydraulic cylinder, a peristaltic pump was used to drip feed oil into the tribo-contact on one side only (Figure 3e,f).

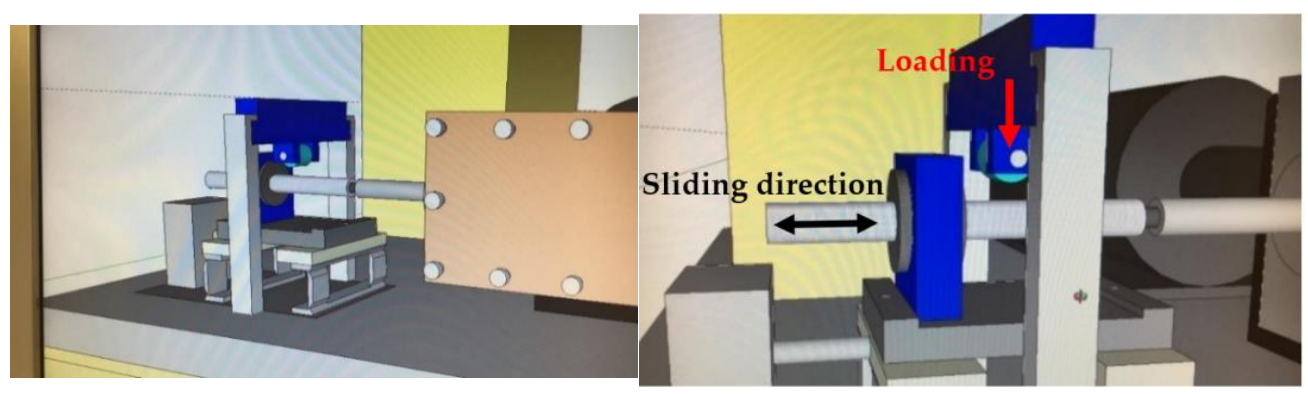

(a)

(b)

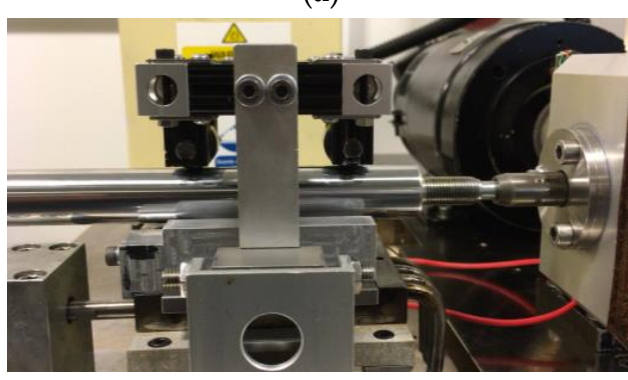

(c)

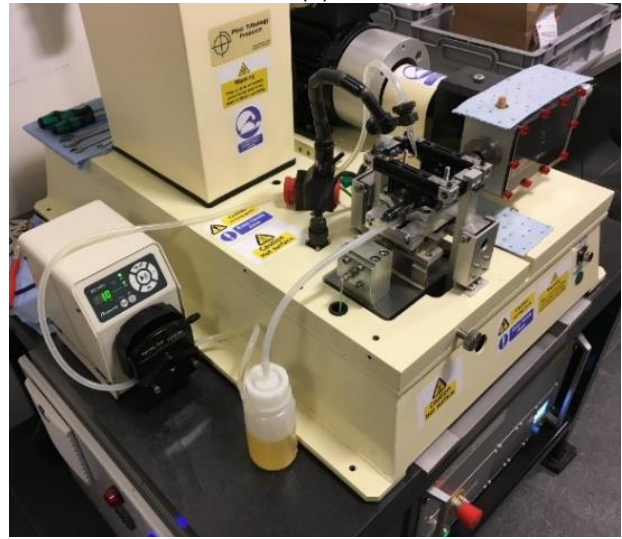

(e)

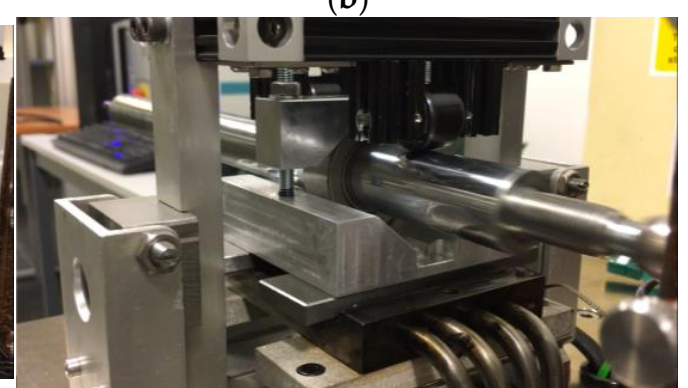

(d)

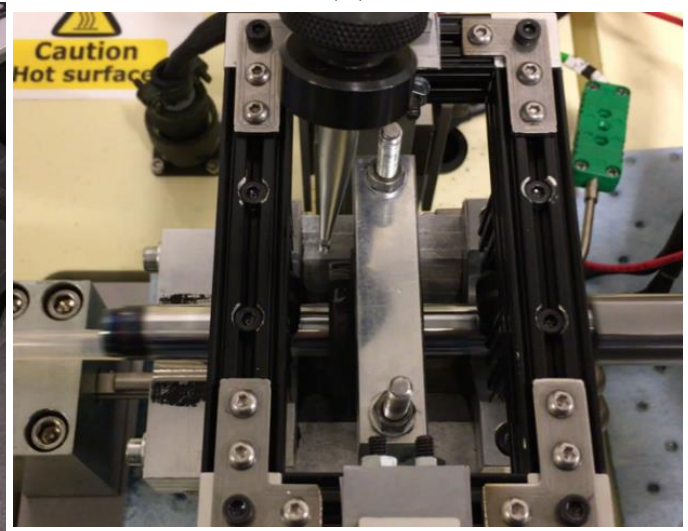

(f)

Figure 3. (a,b) Schematic for updating TE-77 machine to fit and test actual components. (c) Modified holder to fit rod directly onto the driving arm of the TE-77 machine and rollers to apply lateral load. (d) Holder to clamp rod guide onto TE-77 heater plate. (e) Actual hydraulic cylinders tested on adapted TE-77 machine, under lubricated sliding conditions. (f) Drip feeding oil onto the rod.

In these tests, two aspects are evaluated: (a) the friction of the system, which is expressed by the coefficient of friction; and (b) the wear on the coated rod, which indicates material loss. To optimize the test conditions, a series of tests was performed under different loads and times. From these exploratory tests, it was found that trying to accelerate the test by increasing the applied load above $100 \mathrm{~N}$, or not having enough lubrication, can lead to 3 body abrasion (Figure $4 \mathrm{a}$ ) and/or adhesive (Figure 4b) wear mechanisms that are not seen in the field. To mimic the mild abrasive wear from field conditions, we determined optimized test conditions (Table 1). Four different candidate materials were considered: three Ni based variants without (variant I) and with (variants II and III) hard particles and a Cr based variant without any particles. Ni-based variants II and III had different types of particles. Due to confidentially issues, no additional information on the composition and structure of these coatings can be shared. For each batch of coated rods, three repeats were performed on different samples. 


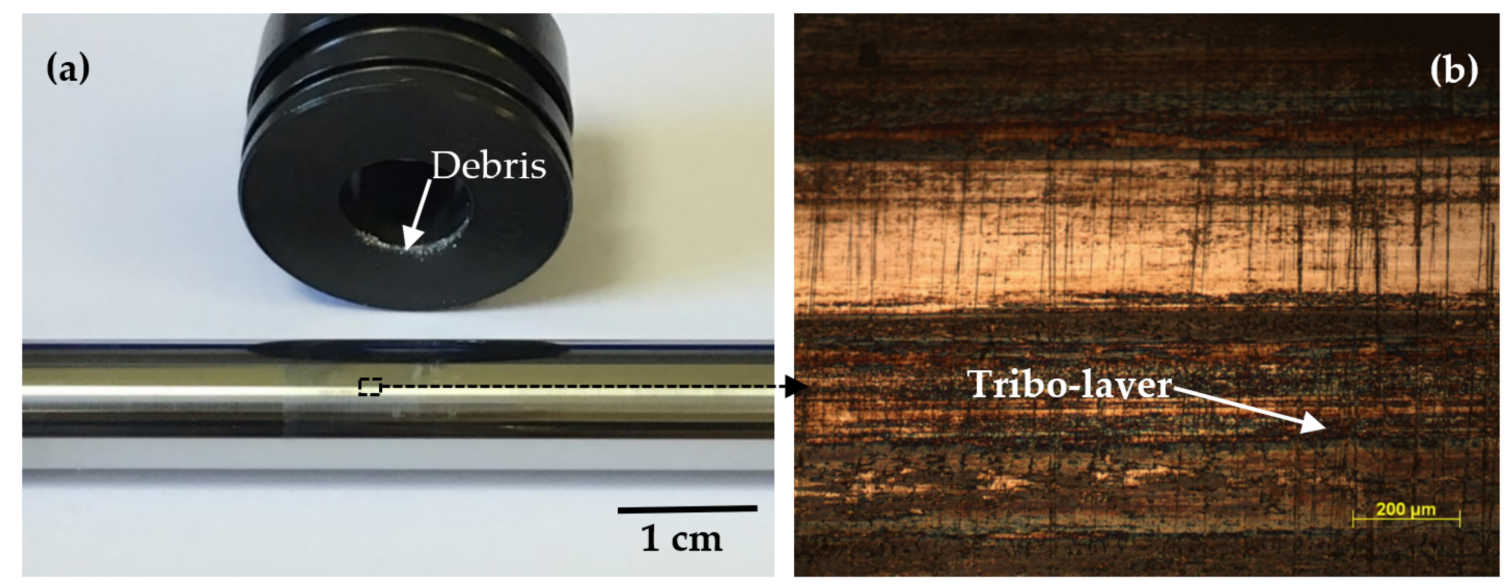

Figure 4. (a) Severe abrasion due to lack of lubrication between the rod and rod guide that leads to the formation of debris particles. (b) Formation of a tribo-layer due to adhesive wear on the rod.

Table 1. Overview of tests performed with optimized experimental conditions for hydraulic cylinder tests.

\begin{tabular}{|c|c|c|c|c|c|c|}
\hline Rod & Rod Guide & Load (N) & $\begin{array}{c}\text { Frequency } \\
\text { (Hz) }\end{array}$ & Stroke (mm) & Test Time (h) & $\begin{array}{c}\text { Lubrication } \\
\text { (mL/min) }\end{array}$ \\
\hline Hard Cr & Anodized Al & 20 & 10 & 21 & 20 & 1 \\
\hline Cr variant & Anodized Al & 20 & 10 & 21 & 20 & 1 \\
\hline Ni variant I & Anodized Al & 20 & 10 & 21 & 20 & 1 \\
\hline Ni variant II & Anodized Al & 20 & 10 & 21 & 20 & 1 \\
\hline Ni variant III & Anodized Al & 20 & 10 & 21 & 20 & 1 \\
\hline
\end{tabular}

After completion of the hydraulic cylinder tests, the rods were analyzed with a $\mu$ Surf Nanofocus confocal microscope to evaluate wear or surface changes, whereas a ZEISS Axio optical microscope was used for a first evaluation of the wear mechanisms.

\section{Results and Discussion}

One of the main advantages of this method in comparison to component tests is that it allows us to monitor the evolution of the coefficient of friction of the rod vs. rod guide during sliding. A typical example of a triplicate test on three different coated (with $\mathrm{Ni}$ variant III) rods is given in Figure 5a. Some differences can be observed during the run-in period, which can be linked to differences in the initial surface topography (see Figure $5 b-d$ ). Indeed, confocal analysis of the rods prior to testing indicated that rods $B$ and $C$ had a higher surface roughness (International Organization for Standardization-ISO 25178) Sa, namely 0.416 and $0.465 \mu \mathrm{m}$, respectively, in comparison to rod A's Sa: $0.268 \mu \mathrm{m}$. After the run-in period of about 8-10 h, the coefficient of friction reaches a steady state, which appears to be very similar for the triplicate tests. This indicates that the method is sensitive enough to detect variations in the coefficient of friction, due to surface topography, for instance. To obtain repeatable measurements, tests should run long enough to achieve stabilization of friction. This is especially important to compare different materials with each other. 


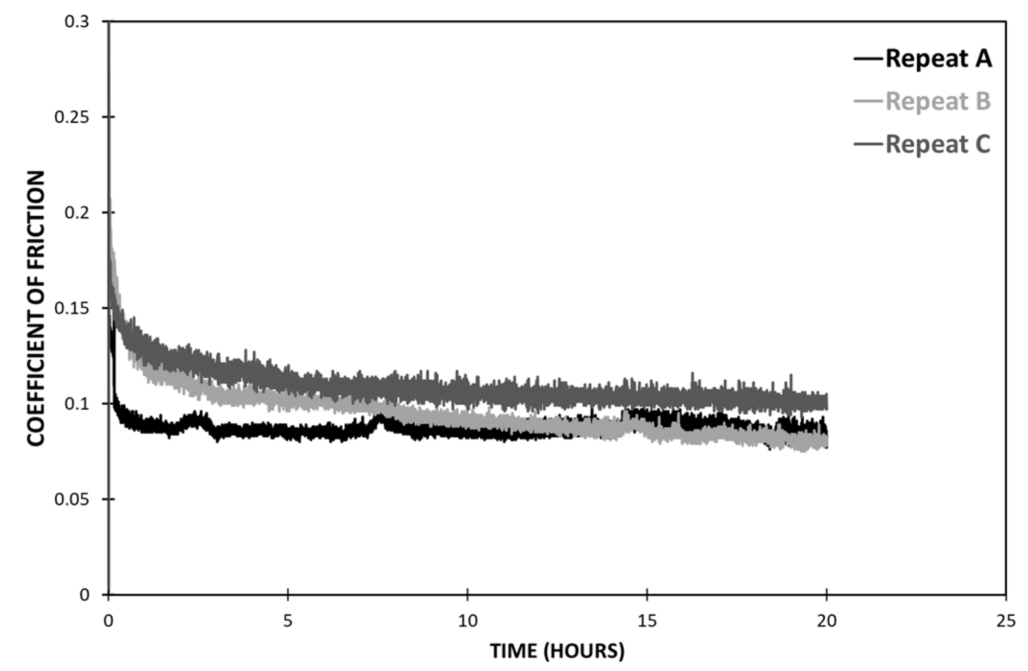

(a)

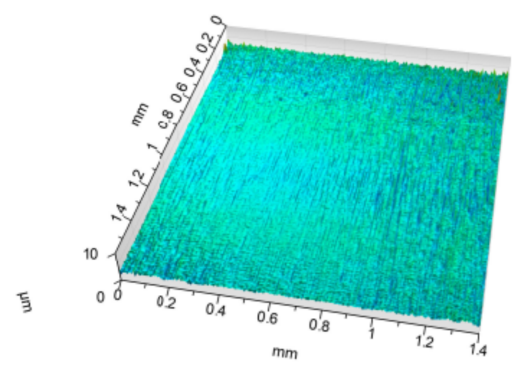

(b)

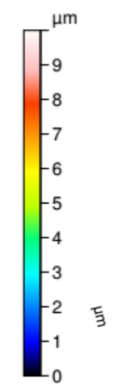

西

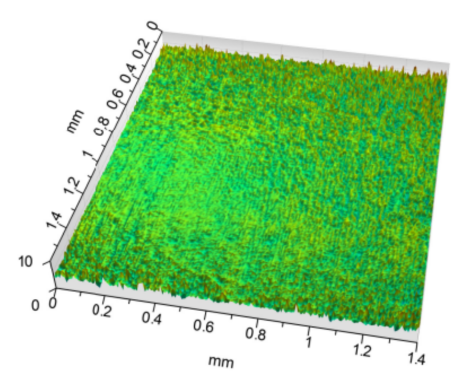

(c)

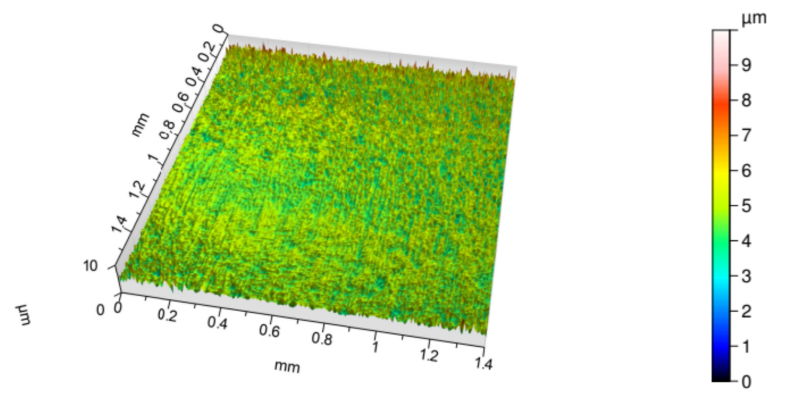

(d)

Figure 5. (a) Evolution of coefficient of friction of coated Ni variant III rods sliding against anodized Al rod guides under lubricated conditions, triplicate tests. Surface topography of these rods prior to testing, used for (b) repeat A, (c) repeat B and $(\mathbf{d})$ repeat $\mathrm{C}$.

The evolution of the coefficient of friction can be used for the relative ranking of the frictional performance of various candidate coatings versus the hard $\mathrm{Cr}$ reference, as seen in Figure 6a. In this way, materials developers can investigate the effect of their plating conditions (Figure $6 \mathrm{~b}$ ), bath composition, etc., on the friction of the rod vs. rod guide. Furthermore, research can also be performed on different rod-guide systems, going, for example, from a lubricated anodized Al to an unlubricated PTFE bearing (Figure 6c). 


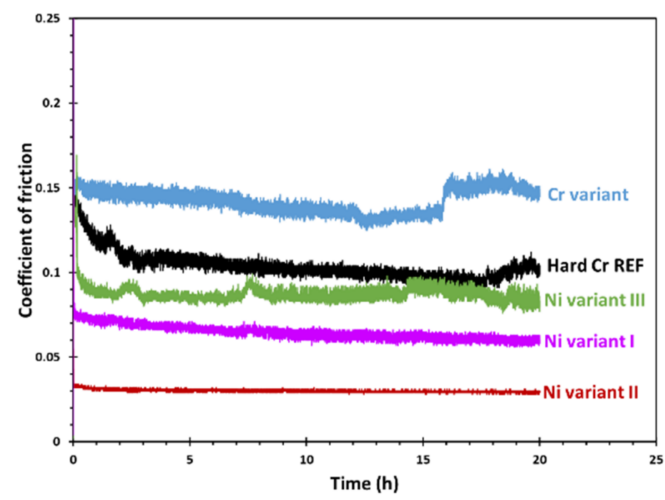

(a)

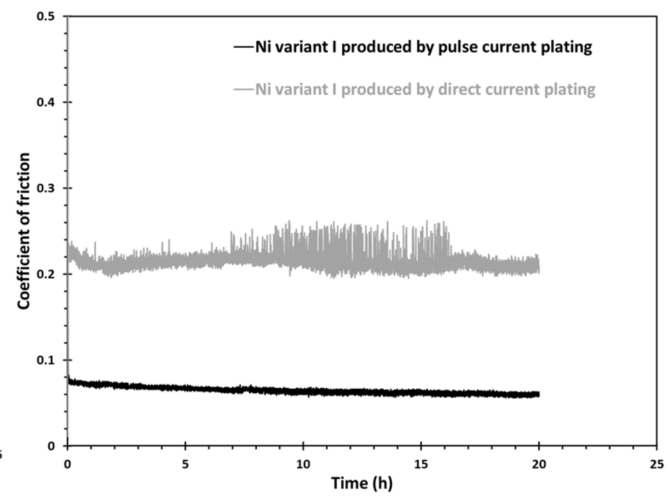

(b)

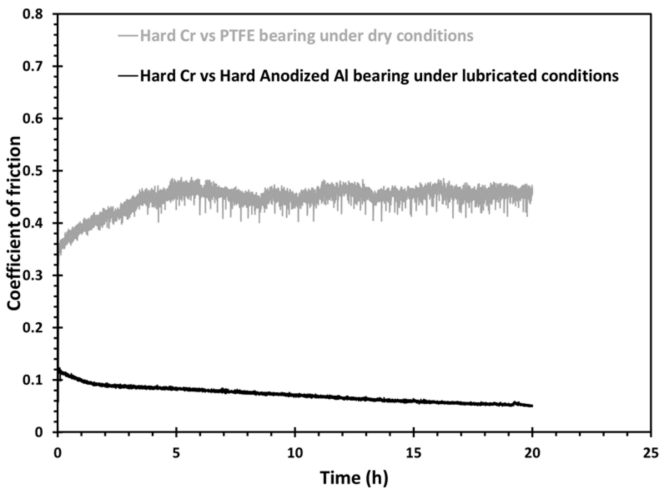

(c)

Figure 6. (a) Evolution of coefficient of friction of for four different optimized candidate coatings and hard $\mathrm{Cr}$ reference rods sliding against anodized $\mathrm{Al}$ rods under lubricated conditions. (b) Effect of plating conditions on the frictional performance of Ni variant I coated rods sliding against anodized $\mathrm{Al}$ rods under lubricated conditions. (c) Friction behavior of different rod guides vs. hard Cr reference rods.

Apart from the friction, a key feature to the functionality of the shock absorbers is their resistance to wear. A typical example of a worn rod and rod guide after 50,000 cycles $(20 \mathrm{~h})$ of testing is given in Figure $7 \mathrm{a}$. The wear of the rod guide was not measurable, so the analysis was mainly performed on the rods. To measure the wear on the rods, multiple profiles were extracted along the sliding direction, as indicated in Figure 7a. In each profile, two reference planes are set, and an area of interest is selected and measured, as shown in Figure $7 \mathrm{~b}$. The reason for selecting 2D over 3D volumetric wear measurements is based on a recent report [27] showing that both approaches provide a similar ranking, but 2D measurements have a lower spread of measurement values.

(a)

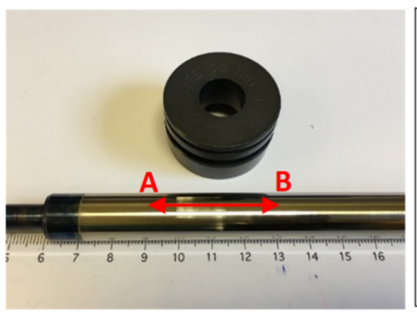

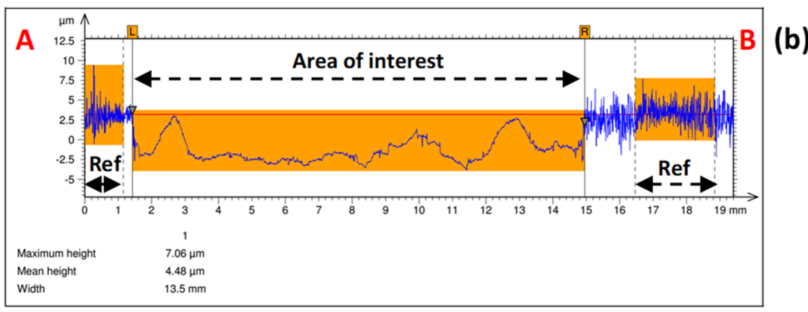

Figure 7. (a) Hard anodized Al rod guide and Ni variant I coated rod after wear testing, and (b) indicative wear profile measured in the middle of the wear track on this rod, along the sliding direction $(\mathrm{A}-\mathrm{B})$. 
Based on this confocal analysis, a relative ranking of candidate coatings and the hard $\mathrm{Cr}$ reference in terms of maximum and mean wear depth can be achieved (Figure 8). From this figure, it can be seen that there are coatings that can potentially replace hard Cr. One common misconception in the world of materials and tribology is that higher hardness necessarily means improved wear resistance. Thus, in many specifications (also in those for hydraulic cylinders), one of the main criteria is hardness, but very few metallic materials can reach the value of hard $\mathrm{Cr}(\approx 1000 \mathrm{HVN})$. However, this is misleading because producers will aim for high hardness, and to achieve this, they typically increase the volume of hard phases (carbides, intermetallics, etc.) in such coatings. However, this leads to risks for the coating's adhesion and cohesion, since they become too brittle. Figure 8 provides a clear example that softer coatings, such as $\mathrm{Ni}$ variant III $(\approx 850 \mathrm{HVN})$, can display lower wear and be an effective replacement in this application. This strictly depends on the tribo-contact, contact conditions and resulting wear mechanisms. Note that these tests are performed in "clean" conditions, in the absence of hard particles that could cause severe abrasion.

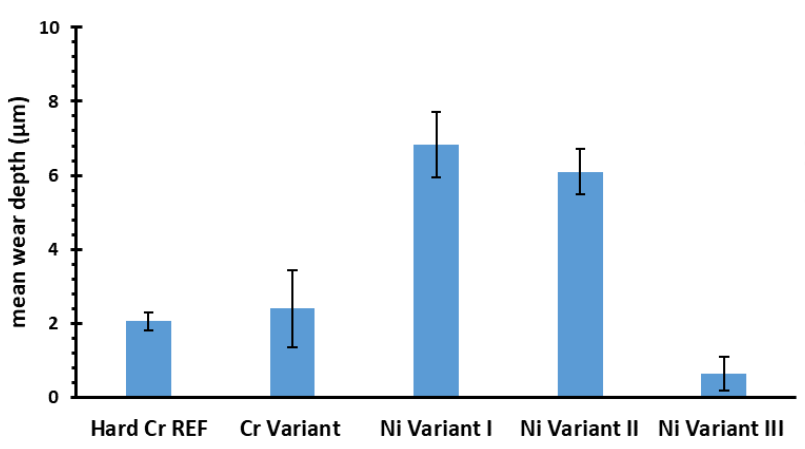

(a)

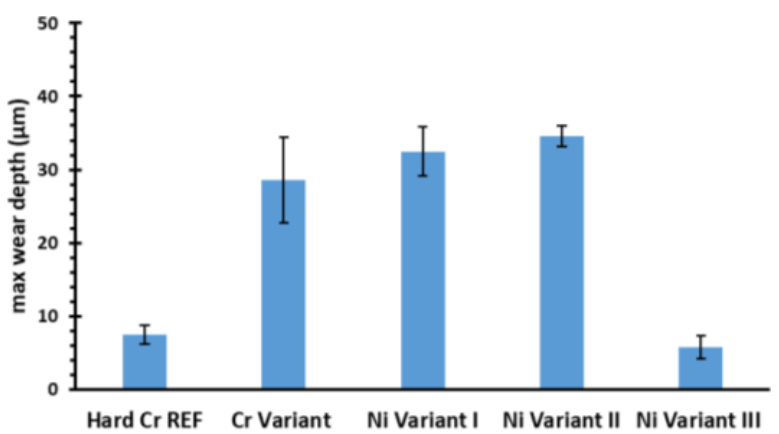

(b)

Figure 8. Comparison of (a) maximum and (b) mean wear depths for four candidate coatings and the hard $\mathrm{Cr}$ reference sliding against anodized $\mathrm{Al}$ rods under lubricated conditions.

To get a better idea on the wear ranking of these coatings, we performed an analysis of the wear tracks by using optical microscopy. Indicative micrographs are given in Figure 9. For the hard $\mathrm{Cr}$ reference and Ni variant III, a mild abrasion wear mechanism is observed, as indicated by the presence of abrasive grooves along the sliding direction (see arrows in Figure 9a,e). The wear morphology of the wear track of these two materials looks very similar. On the other hand, more severe abrasion is seen in the case of Ni variant I and II coatings (Figure 9c,d); this also explains the higher wear depth. Interestingly, when comparing Ni variants I and II, the addition of hard particles did not have a significant effect on the wear resistance of the Ni based matrix, as reported in previous publications [28-30]. The reason is believed to be twofold. It can be due to an inhomogeneous distribution of these particles or to the different tribological conditions. The latter is often neglected, as the majority of lab-scale tribological tests are typically performed under too-high contact pressures (in the popular ball-on-flat geometries) and in dry conditions, to accelerate wear, but the results of such tests cannot be extrapolated to a more complex lubricated tribo-contact or application. 

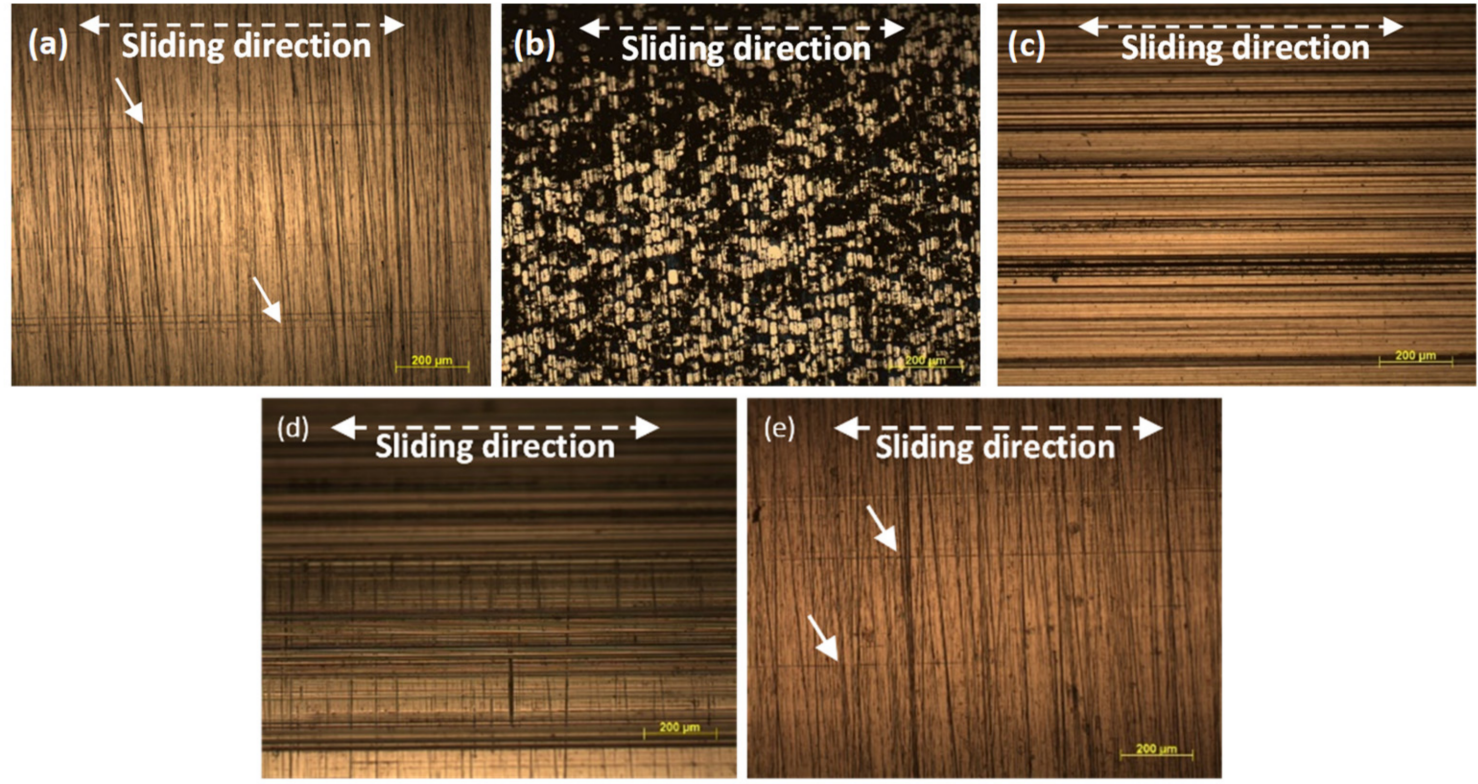

Figure 9. Wear track on (a) hard Cr reference, (b) Cr variant and Ni variants: (c) I, (d) II and (e) III coated rods after sliding against anodized $\mathrm{Al}$ rods under lubricated conditions.

The $\mathrm{Cr}$ variant had comparable mean wear depth to hard $\mathrm{Cr}$ reference but displayed a much higher maximum wear depth (Figure 8). The fluctuation of mean and max wear depth is also much higher than in all the other systems. This is due to initial surface topography of this coating (Figure 10). Indeed, by observing the wear track (Figure 9b), two distinctive areas can be seen: those that were in contact with the hard anodized $\mathrm{Al}$ rod guide and have been polished and those that were outside the tribological contact. Thus, the high variation and value of the maximum wear depth is possibly due to those "intact valleys" of the initial topography. Finally, a comparison between the friction and mean wear (Figure 11) clearly shows that low friction does not necessarily means low wear (see examples of Ni variants I and II), as is frequently assumed a priori.
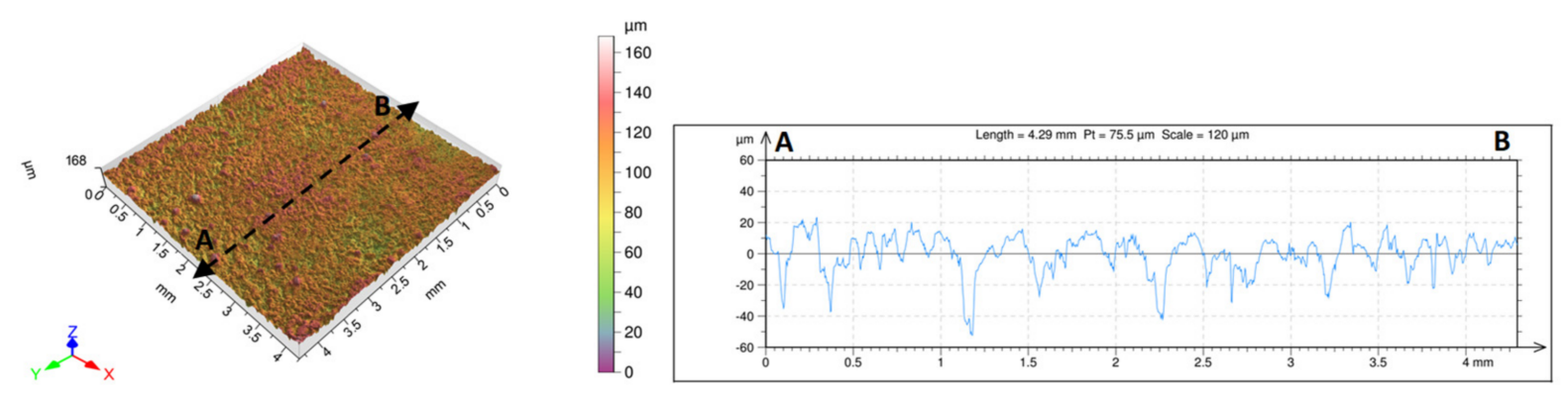

Figure 10. Initial surface topography of Cr-variant-coated rod (A-B is the measurement direction). 


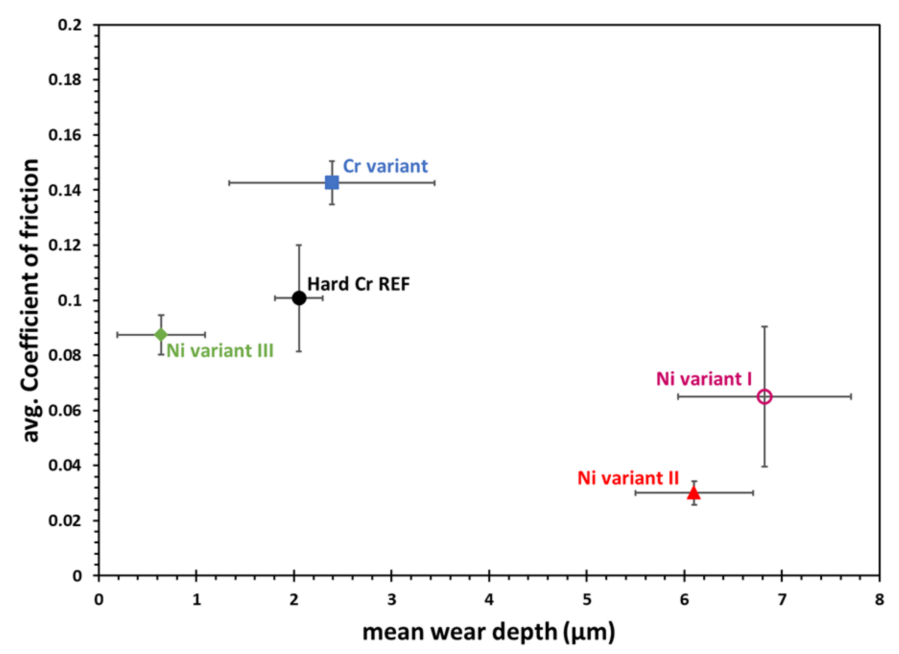

Figure 11. Relative ranking of hard $\mathrm{Cr}$ reference and candidate coatings in terms of mean wear and friction.

\section{Conclusions}

This work proposes a new tribological method to evaluate coatings for a hydraulic cylinder application. In contrast to existing methods, it allows us to directly test on the actual components (rod and rod guides) and provides a relative ranking of both the friction and wear under "relevant" conditions that simulate the actual application well. Furthermore, this method is versatile, repeatable and has a much shorter test duration than the full-scale component tests. To validate this new method, a comparison was performed between different electrodeposited coatings and state-of-the-art hard $\mathrm{Cr}$ reference material. The results clearly showed that electrodeposits can be considered as an alternative replacement to hard Cr. In the future, the authors intend to continue their research in this field and investigate thoroughly the effect of test conditions (e.g., load fluctuation, frequency variation, lubricant quantity and composition, and contamination), as well as rod and rod-guide material variation.

Author Contributions: Conceptualization, E.P.G., D.D. and G.T.; methodology, E.P.G., A.Z.-K., M.P.-F. and L.M.; validation, D.D., E.P.G. and G.T.; formal analysis, A.Z.-K., M.P.-F. and L.M.; investigation, E.P.G.; resources, D.D.; writing — original draft preparation, E.P.G.; writing—review and editing, D.D. and J.-P.C.; visualization, E.P.G.; supervision, J.-P.C.; funding acquisition, E.P.G. and D.D. All authors have read and agreed to the published version of the manuscript.

Funding: This work was part of a Horizon 2020 EU project on PROtective composite Coatings via Electrodeposition and Thermal Spraying (PROCETS Grant Agreement ID: 686135) and a FP7 EU project on New generation of protective coatings alternative to hard chrome (HARDALT Grant Agreement ID: 606110).

Institutional Review Board Statement: Not applicable.

Informed Consent Statement: Not applicable.

Data Availability Statement: Data sharing is not applicable to this article.

Acknowledgments: This work was part of a Horizon 2020 EU project on PROtective composite Coatings via Electrodeposition and Thermal Spraying (PROCETS Grant agreement ID: 686135) and a FP7 EU project on New generation of protective coatings alternative to hard chrome (HARDALT Grant agreement ID: 606110).

Conflicts of Interest: The authors declare no conflict of interest. 


\section{References}

1. Dixon, J.C. The Shock Absorber Handbook, 2nd ed.; John Wiley \& Sons Ltd.: West Sussex, UK, 2007.

2. National Bureau of Statistics. Statistical Communiqué of the 2017 National Economic and Social Development of the People's Republic of China; China Stat: Beijing, China, 2018; pp. 7-20.

3. Guffie, R.K. The Handbook of Hard Chromium Plating, 1st ed.; Gardner Publications: Cincinnati, OH, USA, 1986.

4. Cotell, C.M.; Sprague, J.A.; Smidt, F.A. Handbook of Metals, Surface Engineering; ASM International: Cleveland, OH, USA, 1994; Volume 5.

5. Zarogiannis, P. Environmental Risk Reduction Strategy and Analysis of Advantages and Drawbacks for Hexavalent Chromium; Risk \& Policy Analysts Ltd.: Norwich, UK, 2005.

6. Jeong, D.H.; Erb, U.; Aust, K.T.; Palumbo, G. The relationship between hardness and abrasive wear resistance of electrodeposited nanocrystalline Ni-P coatings. Scr. Mater. 2008, 48, 1067-1072. [CrossRef]

7. Ma, C.; Wang, S.C.; Wang, L.P.; Walsh, F.C.; Wood, R.J.K. The role of a tribofilm and wear debris in the tribological behaviour of nanocrystalline Ni-Co electrodeposits. Wear 2013, 306, 296-303. [CrossRef]

8. Wasekar, N.P.; Sundararajan, G. Sliding wear behavior of electrodeposited Ni-W alloy and hard chrome coatings. Wear 2015, 342, 340-348. [CrossRef]

9. Georgiou, E.P.; Van der Donck, T.; Celis, J.-P. Electrodeposition and structural characteristics of intermetallic nickel-tin based coatings. Trans. Inst. Met. Finish. 2017, 95, 301-307. [CrossRef]

10. Georgiou, E.P.; Kwee, I.S.K.; Van der Donck, T.; Drees, D.; Celis, J.-P. Synthesis, characterization and tribological behavior of electrodeposited nanostructured Co-23 wt.\% Sn coatings. Wear 2019, 430, 290-298. [CrossRef]

11. Weston, D.P.; Shipway, P.H.; Harris, S.J.; Cheng, M.K. Friction and sliding wear behaviour of electrodeposited cobalt and cobalt-tungsten alloy coatings for replacement of electrodeposited chromium. Wear 2009, 88, 934-943. [CrossRef]

12. Ma, C.; Wang, S.C.; Wang, L.P.; Walsh, F.C.; Wood, R.J.K. The electrodeposition and characterisation of low-friction and wear-resistant Co-Ni-P coatings. Surf. Coat. Technol. 2013, 235, 495-505. [CrossRef]

13. Vlaic, C.A.; Kurniawan, M.; Peipmann, R.; Lalău, C.C.; Stich, M.; Schmidt, U.; Bund, A. Improved wear resistance of alternating amorphous and crystalline layers in electrodeposited Ni-P multilayers. Surf. Coat. Technol. 2020, 386, 125470. [CrossRef]

14. Bernasconi, R.; Allievi, F.; Sadeghi, H.; Magagnin, L. Codeposition of nickel-phosphorus alloys reinforced with boron carbide microparticles: Direct and pulse plating. Trans. Inst. Met. Finish. 2017, 95, 52-59. [CrossRef]

15. Wang, S.; Ma, C.; Walsh, F.C. Alternative tribological coatings to electrodeposited hard chromium: A critical review. Trans. Inst. Met. Finish. 2020, 98, 173-185. [CrossRef]

16. Lizarraga, J.; Biera, J.; Sala, J.A. Modelling of friction phenomena in sliding conditions in suspension shock absorbers. Veh. Syst. Dyn. 2008, 46, 751-764. [CrossRef]

17. Zach, C.; Mack, W.; Fruhmann, G.; Tieber, W. On the performance of rheological shock absorber models in full vehicle simulation. Veh. Syst. Dyn. 2007, 45, 981-999. [CrossRef]

18. Gracia, A.G.; Jimenez, F.; Páez, J.; Narváez, A. Theoretical and experimental analysis to determine the influence of the ageing process of the shock-absorber on safety. Int. J. Vehicle Des. 2006, 40, 15-35. [CrossRef]

19. Ryabov, I.V.; Novikov, V.V.; Pozdeev, A.V. Efficiency of shock absorber in vehicle suspension. Procedia Eng. 2016, 150, 354-362. [CrossRef]

20. Zhao, X.; Wang, J. Pump-back effect analysis and wear feature extraction for hydraulic cylinder piston seal based on multi-sensor monitoring. IEEE Trans. Ind. Electron. 2019, 66, 7270-7280. [CrossRef]

21. Kato, S.; Sasaki, S. Effects of hydraulic oil and lubricant additives on dynamic friction properties under various reciprocating sliding conditions. Friction 2020, 8, 471-480. [CrossRef]

22. Ryabov, I.M.; Pozdeev, A.V.; Erontaev, V.V.; Danilov, S.V.; Omarova, Z.K.; Kovalev, A.M.; Silchenkov, D.D. Method for determining the shock absorber effectiveness in the vehicle suspension to ensure its active and operational safety. IOP Conf. Ser. Mater. Sci. Eng. 2019, 632, 012060. [CrossRef]

23. Basso, R. Experimental characterization of damping force in shock absorbers with constant velocity excitation. Veh. Syst. Dyn. 1998, 30, 431-442. [CrossRef]

24. Sheleg, V.K.; Levantsevich, M.A.; Maksimchenko, N.N.; Pilipchuk, E.V.; Yurut, E.L.; Kalach, V.N. Evaluating the applicability of electrodeformation placing technology by a flexible tool for chromeing hydrocilindes. J. Frict. Wear. 2019, 40, 207-212. [CrossRef]

25. ASTM. Standard Test Method for Linearly Reciprocating Ball-on-Flat Sliding Wear; ASTM International: West Conshohocken, PA, USA, 2005.

26. ASTM. The Use of Tribological Aspect Numbers in Bench Test Selection; ASTM International: West Conshohocken, PA, USA, 2001.

27. Georgiou, E.P.; Lopes, L.M.; De Bilde, M.; Drees, D. How can we measure sliding wear in an efficient way? Wear 2020, $458,203414$. [CrossRef]

28. Wu, Y.C.; Li, G.H.; Zhang, L. Wear resistance of electroless deposited Ni-P and Ni-P/SiC composite coatings on low alloy cast iron. Surf. Eng. 2013, 16, 506-510. [CrossRef]

29. Soleimani, R.; Mahboubi, F.; Kazemi, M.; Arman, S.Y. Corrosion and tribological behaviour of electroless Ni-P/nano-SiC composite coating on aluminium 6061. Surf. Eng. 2015, 31, 714-721. [CrossRef]

30. Franco, M.; Sha, W.; Malinov, S.; Liu, H. Micro-scale wear characteristics of electroless Ni-P/SiC composite coating under two different sliding conditions. Wear 2014, 317, 254-264. [CrossRef] 